\title{
Women Fare No Worse Than Men 10 Years After Attempted Coronary Angioplasty
}

\author{
Peter N. Ruygrok, FRACP, Peter P.T. de Jaegere, MD, PhD, Ron T. van Domburg, MSc, \\ Marcel J. van den Brand, MD, PhD, Patrick W. Serruys, MD, PhD, and Pim J. de Feyter, MD, PhD
}

\begin{abstract}
A retrospective review of cardiac events occurring in all patients who underwent attempted coronary angioplasty in the first 5 years of our experlence (1980-1985) was undertaken. Follow-up data were obtained from the civil registry, hospltal records, patient, family, and referring physician. Patient survival curves were constructed and the outcome of women and men was compared. Eight hundred fifty-six patients, 172 women and 684 men with a mean age of 60.0 and 55.3 years, respectively, underwent attempted coronary angioplasty with an overall procedural success rate of $82 \%, 77.7 \%$ in women and $83.1 \%$ in men. Follow-up data were obtained in 837 patients $(\mathbf{9 7 . 8 \% )}$ with a mean period of 9.6 years (range $0-13.3$ years).

The estimated 10 year survival in women was identical to men $[79 \%, 95 \%$ confidence interval (Cl) $72.6-85.4 \%$ vs. $78 \%, 95 \% \mathrm{Cl} 74.6-81.4 \%$ ] as was the 10 year event-free survival (men $36 \%, 95 \% \mathrm{Cl} 32.0-40.0 \%$ vs. women $37 \%$, $95 \%$ Cl $29.2-44.8 \%$ ), with a simllar proportion of major cardiac events-death, myocardial infarction, coronary artery bypass surgery, and repeat angloplasty. When women were matched to men for age and previous myocardial infarction, factors found to be assoclated with an adverse outcome, there was no significant difference. Additionally, outcome was compared after patients were matched for maximum nominal balloon size as an estimate of vessel size, with no significant difference between women and men. At follow-up, women complained of significantly more anginal symptoms than men $(59.2 \%$ vs. $44.0 \%, P<0.05)$ and took significantly more antianginal medication. (1996 Wiley-Liss, Inc.
\end{abstract}

Key words: women, survival, atherosclerosis, coronary angioplasty, prognosis

\section{INTRODUCTION}

Despite major advances in the management of coronary artery disease, not only in surgical and interventional techniques but also in the identification and management of coronary risk factors, it remains the leading cause of morbidity and mortality in both men and women in the Western world. A number of recent reports have focused on the possible inequities in the management of women with obstructive coronary artery disease particularly with regard to revascularization procedures [1-3]. However, when considering the utilization of these techniques, one must take into account the relative risks and benefits of such procedures. It is important to recognize a difference in the demographic, clinical, and angiographic profile of women when compared with men. Women on average are older and have more cardiac risk factors than men and in addition generally have a higher prevalence of unstable angina and congestive heart failure at the time of intervention. The in-hospital mortality after percutaneous transluminal coronary angioplasty (PTCA) increases with age and is higher in women than in men [4-6].
The purpose of this study was to examine the longterm outcome following coronary angioplasty in women compared with men accepting the expected referral bias based on the above observations.

\section{SUBJECTS AND METHODS}

Patients

Between September 1980 and December 1985, PTCA was attempted in 856 consecutive patients, 172 women and 684 men. Patient characteristics are displayed in Table I. The indication for angioplasty was stable angina in 451 patients, unstable angina in 323 , acute myocardial infarction in 76, and other indications in 6 . All patients were treated with a combination of beta-blockers, cal-

From the Catheterization Laboratory, Thoraxcenter, Erasmus University, Rotterdam, The Netherlands.

Received December 13, 1995; revision accepted April 5, 1996.

Address reprint requests to Peter N. Ruygrok, Catheterization Laboratory, Green Lane Hospital, Green Lane West, Auckland 3, New Zealand. 
TABLE I. Characteristics of 856 Patients Who Underwent PTCA In 1980-1985 Divided According to Gender*

\begin{tabular}{lcccc}
\hline & Total & Women & Men & $P$ \\
\hline Number & 856 & 172 & 684 & \\
Age (years) & & & & \\
$\quad$ Mean & 56.3 & 60.0 & 55.3 & $<0.0001$ \\
$\quad$ Range & $22-80$ & $41-78$ & $22-80$ & \\
Indication for PTCA & & & & \\
$\quad$ Stable angina & 451 & $87(50.6 \%)$ & $364(53.2 \%)$ & \\
$\quad$ Unstable angina & 323 & $70(40.7 \%)$ & $253(37.0 \%)$ & \\
MI & 76 & $13(7.6 \%)$ & $63(9.2 \%)$ & NS \\
$\quad$ Other & 6 & $2(0.1 \%)$ & $4(0.1 \%)$ & $<0.05$ \\
Previous MI (\%) & 40 & 34.6 & 43.6 & NS \\
Previous CABG (\%) & 9.1 & 5.9 & 10 & \\
Number of vessels diseased (\%) & & & & \\
$\quad$ One & 63.5 & 68.3 & 62.3 & NS \\
$\quad$ Two & 23.4 & 24.2 & 23.1 & NS \\
$\quad$ Three & 11.7 & 6.2 & 13.2 & 1.4 \\
$\quad$ Main stem & 1.4 & 1.2 & 17.7 & \\
Ejection fraction $<50 \%(\%)$ & 16.5 & 11.9 & & \\
\hline
\end{tabular}

*MI, myocardial infarction; CABG, coronary artery bypass grafting; NS, non-significant.

cium channel blockers, nitrates, and in unstable cases intravenous heparin.

\section{Angioplasty Technique}

At the commencement of the procedure $250 \mathrm{mg}$ acetylsalicylic acid and $100 \mathrm{mg}$ heparin were administered intravenously, with additional boluses of $50 \mathrm{mg}$ given hourly. Following completion of the procedure, if the stability of the immediate result was in doubt, a heparin infusion was commenced to achieve an activated partial thromboplastin time of 2.0-2.5 times control for 12-24 $\mathrm{h}$. All patients continued to receive $40-60 \mathrm{mg}$ nifedipine and $500 \mathrm{mg}$ acetylsalicylic acid daily for a period of at least 6 months. The method of coronary angioplasty changed in February 1983 when the non-steerable catheter system originally described by Grüentzig et al. [7] was replaced by steerable balloon systems [8]. During the study period the angioplasty balloons used were minimally compliant, disposable, and inflated to 6-8 atmospheres in both men and women. Procedural clinical success was defined as a reduction in the luminal narrowing to less than $50 \%$ of the reference diameter, by visual assessment, with no major complications, namely, death, myocardial infarction, coronary artery bypass grafting, or repeat angioplasty, within $24 \mathrm{hr}$ of the procedure. Evidence of myocardial infarction immediately after the procedure was defined by a new $Q$ wave and/or elevation of myocardial enzymes to more than twice the upper limit of normal.

\section{Data Collection and Follow-Up}

Procedural details including maximum balloon size used and complications were recorded at the time of the procedure and entered into a dedicated data base. Procedure-related events were included in all follow-up analyses. All patients who survived hospital were initially checked against the civil registry to establish survival or death. This is a reliable and complete source of mortality data in The Netherlands. Primary endpoints considered at follow-up were death, non-fatal myocardial infarction, recurrent angina pectoris requiring coronary artery bypass surgery, or repeat coronary angioplasty and eventfree survival. These data were retrospectively obtained from the patient by letter or telephone, from family, or from the family doctor, and checked against hospital records.

Assessment of late myocardial infarction in the follow-up period included a history of prolonged chest pain necessitating hospital admission and documentation of a myocardial infarction by electrocardiographic or enzyme criterion. Information on bypass surgery and repeat angioplasty was obtained from the patient and hospital data bases. Additionally, surviving patients were asked for information regarding symptoms of angina pectoris, graded according to the Canadian Cardiovascular Society classification [9], any resultant limitation in activities, and current medication. Follow-up data were obtained on all but $19(2.2 \%)$ patients, the majority of whom had moved abroad. The period of follow-up ranged from 0 to 13.3 years with a median of 9.6 years.

\section{Statistical Methods}

Differences between discrete variables were assessed with the chi-square test. Patient survival curves were constructed according to the method of Kaplan and Meier [10]. $P \leq 0.05$ was considered significant. 


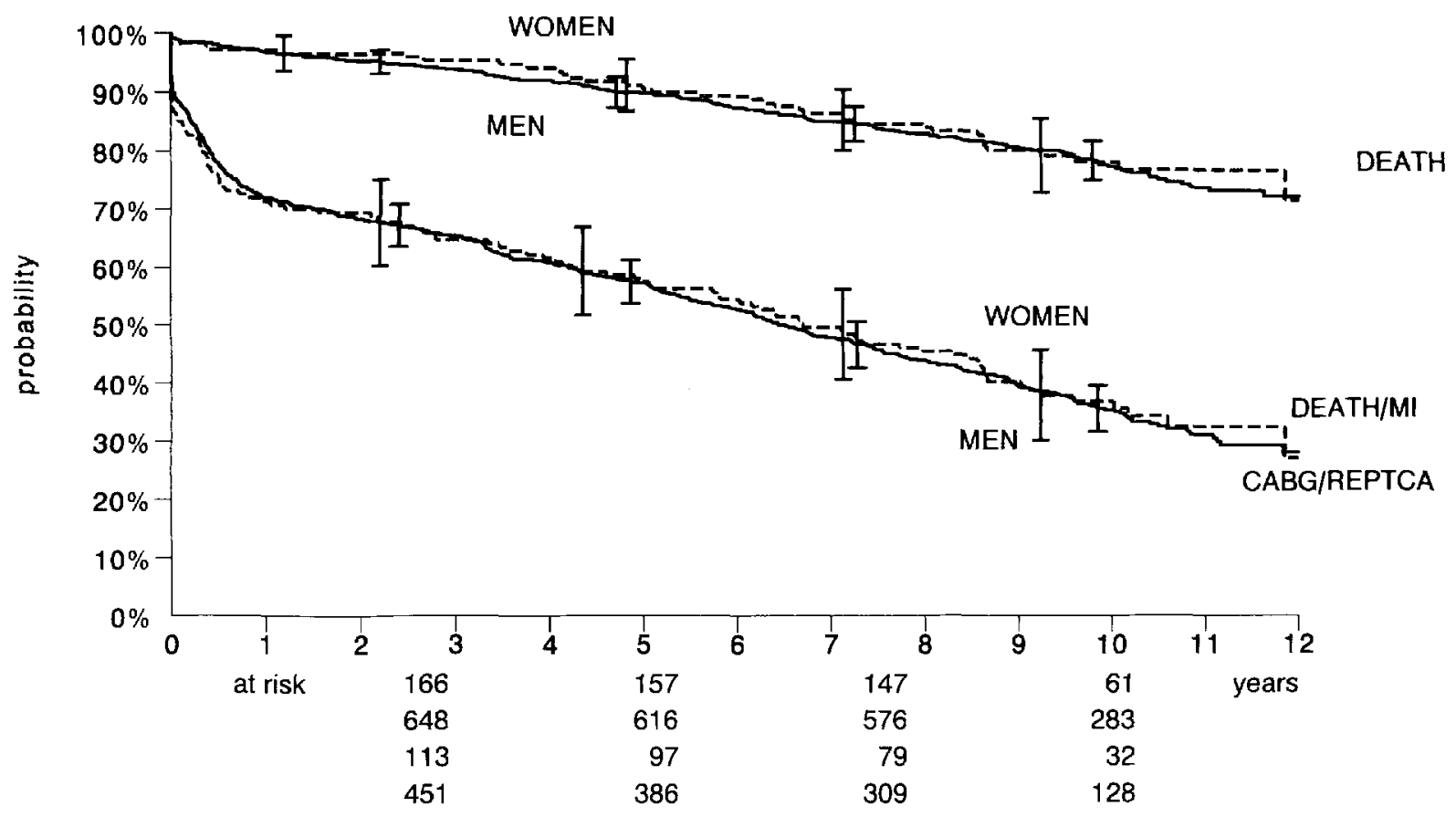

Fig. 1. Cumulative survival and event-free survival rates for men (solid lines) and women (broken lines) who underwent PTCA in 1980-1985 divided according to gender. Numbers are

\section{RESULTS}

In the years 1980-1985, 969 consecutive PTCAs were performed on 856 patients. The procedural success rate was $82 \%$, with $77.7 \%$ of women experiencing a successful angioplasty compared with $83.1 \%$ of men [nonsignificant (NS)]. Three $(1.7 \%)$ women suffered a procedural death compared with $5(0.7 \%)$ men (NS). Long-term follow-up information was obtained on 837 $(97.8 \%)$ patients.

\section{Overall Survival and Events}

Six-hundred forty-one patients were alive $(77 \%)$ and 196 were deceased 8-14 years after their initial angioplasty. One hundred forty-three ( $16.7 \%)$ patients had experienced a myocardial infarction and $220(25.7 \%)$ had undergone coronary artery bypass surgery, $62(7.2 \%)$ as an emergency procedure immediately after coronary angioplasty. Two hundred twenty-one patients underwent further angioplasty in the follow-up period, $81(9.5 \%)$ within 6 months of the initial procedure.

Patient survival and event-free survival curves were calculated. The overall 5 and 10 year patient survivals were $90 \%$ [95\% confidence interval (CI) 87.6-92.4\%] and $78 \%$ (95\% Cl $75.0-81.0 \%)$, respectively, and the 10 year survival with freedom from death, myocardial infarction, coronary artery bypass surgery, or repeat coronary angioplasty was $36 \%$ (95\% CI $32.0-40.0 \%$; 5 patients at risk and vertical lines indicate one standard error. MI, myocardial infarction; CABG, coronary artery bypass grafting.

year freedom from cardiac events $57 \%$, 95\% CI $53.4-$ $60.6 \%$ ). Long-term survival was significantly reduced in patients aged $\geq 60$ years and in those with a history of previous myocardial infarction, multivessel disease, and impaired left ventricular function.

\section{Influence of Gender}

Women were significantly older than men at the time of initial angioplasty with a mean age of 60.0 compared with 55.3 years in men $(P<0.001)$. Additionally, women had suffered fewer myocardial infarctions than men prior to intervention, $34.6 \%$ and $43.6 \%$, respectively $(P<0.05)$. There were no significant differences in the other clinical parameters. Patient survival and event-free survival curves were constructed (Fig. 1). Survival at 10 years was identical for women and men at $79 \%$ (95\% CI 72.6-85.4\%) and 78\% (95\% CI 74.6$81.4 \%$ ), respectively ( 5 year survival $91 \%$ women, $90 \%$ men), as was the incidence of clinical events at $36 \%$ (95\% CI 32.0-40.0\%) for men and $37 \%$ (95\% CI $29.2-$ $44.8 \%$ ) for women with a similar proportion of myocardial infarctions, bypass operations, and repeat coronary angioplasty procedures in the follow-up period (Table II). The mean maximum balloon size used differed between women and men with respective mean diameters of 2.90 and $3.04 \mathrm{~mm}(P<0.0005)$ (Table III). If we use maximum balloon size as an estimation of reference ves- 
TABLE II. Major Cardiac Events Occurring in the Follow-Up Perlod Divided According to Gender

\begin{tabular}{llcc}
\hline & \multicolumn{1}{c}{ Women } & \multicolumn{1}{c}{ Men } & $P$ \\
\hline Death & $39(23.5 \%)$ & $157(23.3 \%)$ & NS \\
Myocardial infarction & $24(14 \%)$ & $119(17.4 \%)$ & NS \\
CABG $^{\mathrm{a}}$ & $43(25.0 \%)$ & $177(25.9 \%)$ & NS \\
Re-PTCA & $43(25.0 \%)$ & $178(26.0 \%)$ & NS \\
\hline
\end{tabular}

${ }^{\mathrm{a} C A B G}$, coronary artery bypass grafting.

sel size, assuming a reference vessel to balloon size ratio of $1: 1$, then women undergoing angioplasty in the study period had significantly smaller vessels than men.

A question that arises from these findings is whether long-term outcome in women is in fact superior to a similar group of men when the negative influences on outcome are taken into account. We therefore matched 172 women with 172 men for age (mean age women 60.03 years, standard deviation 8.07 years vs. mean age men 60.01 years, standard deviation 8.09 years) and previous myocardial infarction (both groups 55 previous infarction, 104 no previous infarction, 13 unknown), factors associated with an adverse outcome, which differed significantly between the two groups; there was no significant difference in 10 year survival (Fig. 2). When we matched 143 women with 143 men for balloon size and compared long-term outcome, there was again no significant difference ( $P=0.27)$ (Fig. 3).

Details of symptomatic status and cardiac medication were obtained in 630 of the 648 survivors (98\%). Angina class, the degree of limitation in 293 of 296 patients with angina, and the number of different antianginal medications from the classes nitrate, beta-blocker, and calcium channel blocker are displayed in Table IV. Significantly more surviving women than men experienced angina with $59.2 \%$ and $44 \%$, respectively, suffering anginal symptoms at the time of interview $(P<0.05)$. In these patients, there was a similar distribution between angina classes I-III and objective assessment of limitation in activities. Women also took significantly more antianginal medication with $70 \%$ on at least one agent compared with $57 \%$ of men.

\section{DISCUSSION}

Women appear to delay the onset of clinically manifest coronary disease by $4-5$ years when compared with men, which is most likely related to the premenopausal protective effect of estrogen $[11,12]$, and one must question whether the older age at presentation results in lower referral and acceptance rates for coronary interventions, possibly explaining the much smaller proportion of women who undergo such procedures. Twenty percent of patients undergoing coronary angioplasty in our institution in the years 1980-1985 were women and they
TABLE III. Maximum Nominal Balloon Size Used During Angioplasty: Comparison of Women and Men

\begin{tabular}{lcc}
\hline Balloon size $(\mathrm{mm})$ & Women & Men \\
\hline 2.0 & $12(7.6 \%)$ & $36(5.6 \%)$ \\
2.5 & $28(17.8 \%)$ & $70(10.9 \%)$ \\
3.0 & $101(64.3 \%)$ & $388(60.5 \%)$ \\
3.5 & $6(3.8 \%)$ & $41(6.4 \%)$ \\
3.75 & $10(6.4 \%)$ & $104(16.2 \%)$ \\
$\geq 4.0$ & $0-$ & $2(0.3 \%)$ \\
Mean & & 3.04 \\
Standard deviation & 0.40 & 0.44 \\
\hline
\end{tabular}

${ }^{*} P<0.0005$.

were on average 4.7 years older $(P<0.0001)$, had suffered less myocardial infarction $(P<0.05)$, undergone less prior coronary artery bypass surgery, had less chance of impaired left ventricular function, and were less likely to have multivessel disease than men over the same period, findings consistently reported by others (Table V). Additionally women undergoing angioplasty have been found to have a greater chance of having unstable angina and an increased likelihood of an adverse risk factor profile at the time of intervention $[6,13]$.

Overall 5 year survival was $90 \%$ (91\% for women and $90 \%$ for men) which, although favorable, appears to be at the lower limit of previously reported data, where 5 year survival ranges from 89.2 to $96.3 \%$ [16-18]. However, one must recognize the variation in patient populations; e.g., one may expect a better outcome following a successful angioplasty in a patient with stable angina and single vessel disease, where the prognosis is excellent even with medical therapy [19]. In our study, all patients in whom coronary angioplasty was attempted were included for analysis including those with angioplasty for an acute myocardial infarction. We felt this population more closely resembles the cross-section of current angioplasty practice. Several studies have found that outcome in terms of survival and major cardiac events, up to 5 years following angioplasty, is similar in women and men once the higher rate of in-hospital events has been accounted for $[4,6,13]$. These observations have been extended to the long-term by our study. Ten year survival was $79 \%$ for women and $78 \%$ for men and event-free survival was identical at $36 \%$. When women and men were matched for age and a history of a previous myocardial infarction, factors found to be associated with a significantly poorer long-term outcome in our study, no significant difference was found. One can suggest that a balance has been found between the favorable and non-favorable clinical factors in the selection of women referred for interventional procedures such that their outcome in the long-term is the same as that for men. The only other study reporting 10 year survival is that of King and Schlumpf [20], who described the long- 




Fig. 2. Cumulative survival and event-free survival rates for $\mathbf{1 7 2}$ women (broken lines) matched with 172 men (solid lines) from the same period for age and history of previous myocardial infarction (MI). CABG, coronary artery bypass grafting. Numbers and lines as in Figure 1.

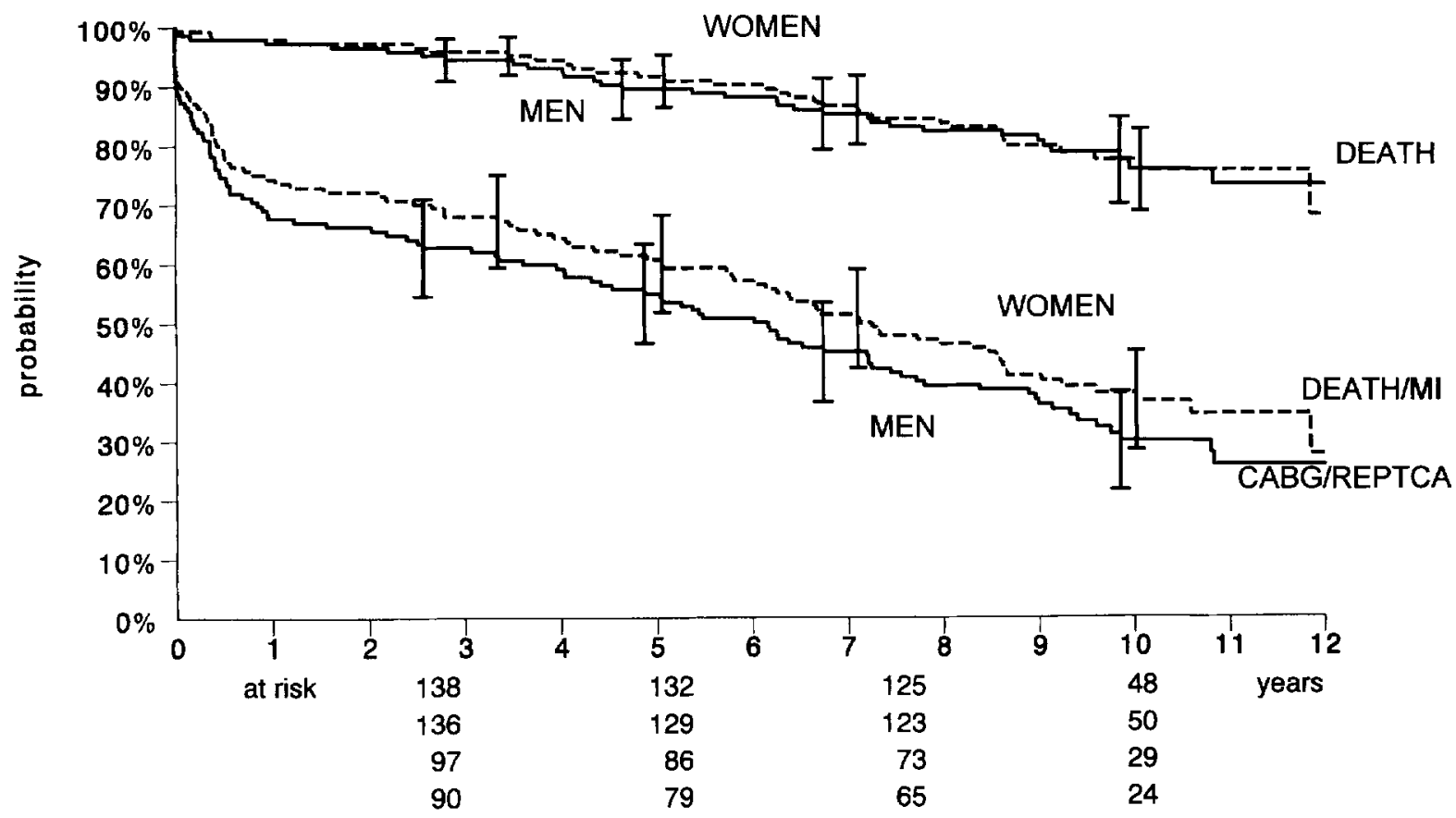

Fig. 3. Cumulative survival and event-free survival rates for 143 women (broken lines) matched with 143 men (solid lines) for maximal nominal balloon size. MI, myocardial infarction; CABG, coronary artery bypass grafting. Numbers and lines as in Figure 1.

term outcome of Grüentzig's first 169 coronary angioplasty patients. In this group of relatively young, highly selected patients, 10 year survival was $89.5 \%$. Although the study populations are not comparable, particularly with respect to the proportion of multivessel disease, it is of interest to note that the 10 year survival of the Coro- 
TABLE IV. Symptomatic Status and Antianginal Medication of Surviving Patients Divided According to Gender $(\mathbf{N}=\mathbf{6 3 0})$

\begin{tabular}{lccc}
\hline & Women & Men & $P$ \\
\hline Angina class & & & \\
0 & $51(40.8 \%)$ & $283(56.0 \%)$ & \\
I & $16(12.8 \%)$ & $49(9.7 \%)$ & \\
II & $31(24.8 \%)$ & $103(20.4 \%)$ & \\
III & $27(21.6 \%)$ & $70(13.9 \%)$ & \\
IV & 0 & 0 & $<0.05$ \\
Limitation in activities (symptomatic patients) (\%) & & & \\
No limitation & 13.5 & 17.4 & \\
Mild limitation & 68.9 & 67.1 & NS \\
Severe limitation & 17.6 & 15.5 & \\
Antianginal medication (\%) & & & \\
$\quad$ None or aspirin & 29.8 & 43.0 & $<0.05$ \\
Single therapy & & & \\
Double therapy & 33.1 & 30.9 & 18.2 \\
Triple therapy & 26.6 & 7.9 & \\
\hline
\end{tabular}

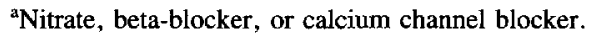

TABLE V. Comparison of Reported Baseline Characteristics of Women and Men Who Underwent Coronary Angioplasty*

\begin{tabular}{|c|c|c|c|c|c|c|c|c|c|c|c|c|}
\hline & \multicolumn{2}{|c|}{ Bell et al. [4] } & \multicolumn{2}{|c|}{ Kelsey et al. [6] } & \multicolumn{2}{|c|}{ Weintraub et al. [13] } & \multicolumn{2}{|c|}{ McEniery et al. [14] } & \multicolumn{2}{|c|}{ Arnold et al. [15] } & \multicolumn{2}{|c|}{ Present study } \\
\hline & Women & Men & Women & Men & Women & Men & Women & Men & Women & Men & Women & Men \\
\hline Number & 824 & 2,203 & 546 & 1,590 & 2,845 & 7,940 & 969 & 2,727 & 1,274 & 3,726 & 172 & 684 \\
\hline Proportion & 27 & 73 & 25.6 & 74.4 & 26.3 & 73.7 & 26.2 & 73.8 & 25 & 75 & 20.1 & 79.9 \\
\hline Mean age (years) & 66 & 61 & 61.0 & 56.5 & 62 & 57 & 61 & 57 & 61.5 & 57.5 & 60.0 & 55.3 \\
\hline Unstable angina & 75.8 & 67.5 & 60.4 & 49.9 & - & - & 26 & 16 & 58.6 & 47.8 & 40.6 & 37.0 \\
\hline Previous MI & 51.9 & 54.1 & 31.5 & 36.8 & 31.0 & 35.4 & 32 & 34 & 31.5 & 36 & 34.6 & 43.6 \\
\hline Previous CABG & 8.7 & 14.7 & 9.9 & 12.6 & - & 一 & 9 & 15 & 10 & 14.6 & 5.9 & 10 \\
\hline MV disease & 63.1 & 65.3 & 51.6 & 51.3 & 25.2 & 31.0 & - & - & - & - & 31.7 & 37.7 \\
\hline $\mathrm{EF}<50 \%$ & - & - & 13.5 & 20.5 & 14.4 & 17.6 & - & - & 9.2 & 11.8 & 11.9 & 17.7 \\
\hline
\end{tabular}

*Data are percentages except where indicated. MI, myocardial infarction; CABG, coronary artery bypass grafting; MV, multivessel; EF, ejection fraction.

nary Artery Surgery Study (CASS) registry patients who were initially assigned surgical management was $70 \%$ for women and $73 \%$ for men [21].

The influence of vessel size on outcome has been of interest and is relevant when comparing the outcome of coronary angioplasty in men and women. The outcome of surgical revascularization in women who have a smaller body surface area has been reported to be less favorable than in men $[22,23]$. It has been found that adjusting for body surface area, a surrogate for coronary artery size [24], appears to remove the influence of gender on immediate outcome following coronary angioplasty $[15,25]$ and that a larger body surface area may confer a more favorable long-term outcome [13]. As an estimation of coronary vessel size we used the nominal size of the largest angioplasty balloon used during angioplasty procedure. We believe the assumption of a $1: 1$ ratio of maximal balloon size to reference vessel diameter, or at least a consistent ratio in men and women, to be a valid one, although making this assumption in the absence of data remains a limitation of our study. The maximum balloon size was significantly smaller in women, thus suggesting smaller coronary arteries. When men and women were matched for this variable there was no significant difference in long-term outcome, although there was a trend toward improved event-free survival in women. The reasons are speculative but may be related to the superior cardiac status of women at the time of intervention as outlined above. Additionally, it has been suggested recently that atherosclerotic lesions in women are less likely to have calcium than lesions with a similar degree of luminal narrowing in men [26], the presence of calcium being a factor associated with a less favorable procedural result [27].

Our finding of significantly more angina in surviving women than in men $(59 \%$ vs. $44 \%)$ is consistent with the findings of others, with women appearing to have a $20-$ $40 \%$ increased chance of suffering anginal symptoms at follow-up than men $[6,13,14]$. Additionally, women in our study took significantly more antianginal medication (beta-blocker, calcium channel blocker, and/or nitrate) than men, an observation also previously reported $[6$, 
14]. Thus, it appears that for a comparable risk of an adverse cardiac event in the long-term, women achieve less symptomatic relief than men.

\section{CONCLUSIONS}

Women selected to undergo PTCA are older, have more unstable angina, and on the whole have less complex cardiac disease than men. Their long-term prognosis following attempted coronary angioplasty is good and identical to that of men with respect to survival and incidence of major cardiac events. However, in the longterm, women are more likely to retain or have a recurrence of anginal symptoms and more frequently require antianginal medication than men.

\section{REFERENCES}

1. Ayanian JZ, Epstein AM: Differences in the use of procedures between women and men hospitalized for coronary heart disease. $N$ Engl J Med 325:221-225, 1991.

2. Mark DB, Shaw LK, deLong ER, Califf RM, Pryor DB: Absence of sex bias in the referral of patients for cardiac catheterization. $\mathrm{N}$ Engl J Med 330:1101-1106, 1994.

3. Tobin JN, Wassertheil-Smoller S, Wexler JP, et al.: Sex bias in considering coronary bypass surgery. Ann Int Med 107:19-25, 1987.

4. Bell MR, Grill DE, Garratt KN, Berger PB, Gersh BJ, Holmes DR: Long-term outcome of women compared with men after successful coronary angioplasty. Circulation 91:2876-2881, 1995.

5. Cowley MJ, Mullin SM, Kelsey SF, et al.: Sex differences in early and long-term results of coronary angioplasty in the NHLBI PTCA Registry. Circulation 71:90-97, 1985.

6. Kelsey SF, James M, Holubkov AL, et al.: Results of percutaneous transluminal coronary angioplasty in women. 1985-1986 National Heart, Lung, and Blood Institute's coronary angioplasty registry. Circulation 87:720-727, 1993.

7. Grüentzig AR, Senning A, Sieganthaler WE: Nonoperative dilatation of coronary-artery stenosis: Percutaneous transluminal coronary angioplasty. $\mathrm{N}$ Engl $\mathrm{J}$ Med 301:61-67, 1979.

8. Simpson JB, Baim DS, Robert EW, et al.: A new catheter system for coronary angioplasty. Am J Cardiol 49:1216-1222, 1982.

9. Campeau L: Grading of angina pectoris (letter). Circulation 54: 522-523, 1975.

10. Kaplan EL, Meier P: Nonparametric estimation of incomplete observations. J Am Stat Assoc 53:457-481, 1958.

11. Wenger NK, Speroff L, Packard B: Cardiovascular health and disease in women. N Engl J Med 329:247-256, 1993.

12. Barrett-Connor E, Bush TL: Estrogen and coronary heart disease in women. JAMA 265:1861-1867, 1991.
13. Weintraub WS, Wenger NK, Kosinski AS, et al.: Percutaneous transluminal coronary angioplasty in women compared with men. J Am Coll Cardiol 24:81-90, 1994.

14. McEniery PT, Hollman J, Knezinek V, et al.: Comparative safety and efficacy of percutaneous transluminal coronary angioplasty in men and women. Cathet Cardiovasc Diagn 13:364-371, 1987.

15. Arnold AM, Mick MJ, Piedmonte MR, Simpendorfer C: Gender differences for coronary angioplasty. Am J Cardiol 74:18-21, 1994.

16. Henderson RA, Raskino C, Karani S, Sowton E: Comparative long-term results of coronary angioplasty in single and multivessel disease. Eur Heart J 13:781-786, 1992.

17. Kadel C, Vallbracht C, Buss F, Kober G, Kaltenbach M: Longterm follow-up after percutaneous transluminal coronary angioplasty in patients with single-vessel disease. Am Heart J 124: $1159-1169,1992$.

18. Talley JD, Hurst JW, King SB, et al.: Clinical outcome 5 years after attempted percutaneous transluminal coronary angioplasty. Circulation 77:820-829, 1988.

19. Coronary Artery Surgery Study (CASS): A randomized trial of coronary artery bypass surgery survival data. Circulation 68:939$950,1983$.

20. King SB, Schlumpf M: Ten year completed follow-up of percutaneous coronary angioplasty: The early Zurich experience. J Am Coll Cardiol 22:353-360, 1993.

21. Davis KB, Chaitman B, Ryan T, Bittner V, Kennedy W: Comparison of 15-year survival for men and women after initial medical or surgical treatment for coronary artery disease: A CASS registry study. J Am Coll Cardiol 25:1000-1009, 1995.

22. Loop FD, Golding LR, MacMillan JP, Cosgrove DM, Lytle BW, Sheldon WC: Coronary artery surgery in women compared with men: Analyses of risks and long-term results. J Am Coll Cardiol 1:383-390, 1983.

23. Fisher LD, Kennedy JW, Davis KB, et al.: Association of sex, physical size and operative mortality after coronary artery bypass surgery in the Coronary Artery Surgery Study (CASS). J Thorac Cardiovasc Surg 84: 334-341, 1982.

24. Roberts CS, Roberts WC: Cross-sectional area of the proximal portions of the three major epicardial arteries in 98 necropsy patients with different coronary events: Relationship to heart weight, age and sex. Circulation 62:953-959, 1980.

25. Bell MR, Holmes DR, Berger PB, Garratt KN, Bailey KR, Gersh BJ: The changing in-hospital mortality of women undergoing percutaneous transluminal coronary angioplasty. JAMA 269:2091$2095,1993$.

26. De Vries S, Wolfkiel C, Fusman B, et al.: Influence of age and gender on the presence of coronary calcium detected by ultrafast computed tomography. I Am Coll Cardiol 25:76-82, 1995.

27. Savage MP, Goldberg S, Hirschfeld JW, et al.: Clinical and angiographic determinants of primary coronary angioplasty success. J Am Coll Cardiol 17:22-28, 1991. 